\title{
Toward a law of healthy peoples: From the Perspective of the Right to Health
}

\author{
Yusheng Tan \\ Ph.D. in Law, Associate Professor, Guangdong University of Petrochemical Technology \\ (Maoming, China) \\ E-mail: 530700069@qq.com \\ https://orcid.org/0000-0002-2645-0611
}

Tan, Yusheng (2020) Toward a law of healthy peoples: From the Perspective of the Right to Health. Future Human Image, Volume 13, 2020: 113-125. https://doi.org/10.29202/fhi/13/12

With the outbreak of the Coronavirus disease (COVID-19) pandemic, the international community is forced to face the global health crisis again. Even though, throughout the course of history, the human race has seldom succeeded in getting rid of infectious diseases and global health inequalities completely. Faced with this tragic situation and extreme inequality, some philosophers have put forward some exciting plans, and it is undoubtedly regrettable that Rawls, one of the most outstanding contemporary political philosophers and ethicists, has not addressed this issue in his The Law of Peoples. However, if Rawls wants its philosophical blueprint for the future world - the law of peoples as a "realistic utopia" to be feasible, he has to face the challenges of global health and make a reasonable response. Otherwise, the magnificent building of this "realistic utopia" will collapse. Therefore, the author tries to develop Rawls' international justice theory by introducing the idea of the right to health into the law of peoples, so as to hopefully provide a feasible philosophical plan to solve the global health problems.

Keywords: Global health, John Rawls, The Law of Peoples, the Right to Health

Received: March 30, 2020; accepted: April 22, 2020

\section{Introduction}

Human history is arguably the history of combating diseases, especially infectious diseases. The most prominent of these diseases are plague, cholera, and smallpox, which once and still caused havoc on humanity. Conditions such as tuberculosis that were thought to be under control have been resurgent in recent years. Even more worrying and scaring is the emergence of new malignant diseases, whether AIDS or Severe Acute Respiratory Syndrome (SARS) and also the current COVID-19. With the outbreak of the Coronavirus disease (COVID-19) pandemic, the international community is forced to face the global health crisis again.

(C) Tan, Yusheng, 2020 
But the fact is not that simple. More precisely, the above statement does not have much to do with people in rich countries in some ways. $60 \%$ of the population in the world's poorest countries will die from infectious diseases, compared with less than $10 \%$ in rich countries. ${ }^{1}$ Cholera, plague, and other diseases have been sporadic in developed countries. As for AIDS, which had once spread in some developed countries, developed countries were now far lower than developing countries owing to extensive health education and the use of effective antiviral drugs, both in terms of infection rate and mortality.

In addition to being more vulnerable to infectious diseases, people living in developing countries are far less likely to have access to clean water, basic sanitation, antenatal care, and basic immunization services than members of developed countries. In this way, there is a huge difference between people in different countries in the opportunity to sustain life itself. In 2017, Sub-Saharan Africa and Southern Asia accounted for approximately $86 \%(254,000)$ of the estimated global maternal deaths with sub-Saharan Africa alone, accounting for roughly $66 \%(196,000) .^{2}$

Perhaps nothing else in the world is more shocking than the huge gap between life and death opportunities. Confronted with this unequal situation, philosophers need to reflect: what measures should be taken to change the current situation? What moral obligations should developed countries assume for developing countries? What kind of goal or ideal should we pursue is the most fair and desirable?

\section{Philosophers' plan: from Peter Singer to Thomas Pogge}

\section{Singer's principle of equal consideration of interests and positive duty to assist}

Peter Singer, one of the most famous contemporary philosophers, studied global health early in the 1970s when millions of Bangladeshi people in East Bengal were suffering from severe hunger and death threats due to lack of necessary food, shelter and health care. Should people in rich countries assist these refugees in such circumstances? Singer gave a positive answer. Singer's argument is like this

A1 The suffering and death caused by lack of necessary food, shelter and medical measures are evil,

A2 If, within our means, we can prevent such suffering and death without sacrificing even a little bit of comparable moral importance, then morally, we ought to do so.

If these two premises are correct, then

B1 Bangladesh refugees are now under the threat of suffering and death described in A1,

B2 As a member of the developed world, we can only donate a very small part of our income without sacrificing anything of comparable moral importance to convert into food and medicine urgently needed by the victims, thus preventing the occurrence of death, which undoubtedly meets the conditions described in A2.

Therefore, the conclusion can only be that we should assist the victims without delay.

By "without sacrificing anything of comparable moral importance" Singer means "without causing anything else comparably bad to happen, or doing something wrong in itself, or failing to promote some moral good, comparable in significance to the bad thing that we can prevent" (Singer, 1972). Singer points out, The idea of "moral importance" does not need to be distinguished, because it can be proved without any particular value or ethical principle. B2

\footnotetext{
${ }^{1}$ www.oneworldhealth.org/global_burden last visited on 9 March, 2015.

2 www.who.int/news-room/detail/19-09-2019-maternal-deaths-decline-slowly-with-vast-inequalities-worldwide, last visited on 20 January, 2020.
} 
is right for the vast majority of people living in industrialized countries, whatever defensible "moral importance" point of view.

Singer's argument is based on the principle of equality in the weakest since - the principle of "equal consideration of interests," the essence of which is that in ethical prudence, we should give equal consideration to the similar interests of all those affected by our actions. This means that if a possible action only affects $\mathrm{X}$ and $\mathrm{Y}$, and if the $\mathrm{X}$ loses more than the $\mathrm{Y}$ gains, it is preferable not to take such action. By accepting the principle, we can not say that, despite the above description, because we care more $Y$ than care $X$, it is better to act in this way than not. The true meaning of the principle is: "an interest is an interest, whoever's interest it may be" (Singer, 2011). The basic element of this principle is that, when considering the interests of the person concerned (whatever their interests), it must apply to everyone, regardless of race, sex, or IQ.

Singer acknowledged that, in some cases, the principle of equal consideration of interests could lead to unequal outcomes. Suppose that after the earthquake, we encountered two wounded persons, one of whom had lost one leg and was also at risk of losing one toe on the other leg; the other was less injured, and one leg, though injured, was expected to be preserved. Unfortunately, our medical supplies are just enough for one casualty. If we use them for the former, we can only save one toe at most; if we use them for the latter, we can save one leg. Faced with this dilemma, what should we do? Singer thinks we should use medicine to keep the latter's legs. Out of impartial consideration, if we use our limited medical resources for the less seriously wounded, then we can better promote the interests of those affected by our actions. After all, the loss of one leg is more serious than the loss of one toe. And this is what the principle of equal consideration of interests requires us to do. "Thus, equal consideration of interests can, in special cases, widen rather than narrow the gap between two people at different levels of welfare. It is for this reason that the principle is a minimal principle of equality, rather than a thorough-going egalitarian principle" (Singer, 2011).

Based on the principle of equal consideration of interests, Singer believes that people in rich countries should not hesitate to assist the poor in other countries. What criteria should be adopted for such assistance? Singer argues that anyone in affluent societies who has enough money to spend on luxury goods and leisure should donate at least $1 \%$ of their income to people who have difficulty getting enough food, clean drinking water, basic shelter, and medical care. Those who fail to meet this donation standard should be seen as failing to fulfill their fair share of global responsibility and thus making a severe moral mistake. But Singer still stresses that this is a minimum Standard. Those who think carefully about their ethical obligations will realize that they should pursue a higher standard (Singer, 2016).

Singer's argument, which focuses on near-death and related relief from famine and extreme poverty, does not add much to his discussion about how we ought to do beyond that. At the same time, I agree with Michael Black that Singer mainly regards the moral choice of actors as the core of his analysis. The actors here sometimes represent the government, but more often represent the individual, and need to decide whether to spend money on individual plans or desires, or on saving the lives of the poor on the death line. But the problem with this approach is that in the domestic field, we not only pay attention to personal morality, but also pay attention to the moral judgment of social institution and practice, that is, political morality. A complete global ethic, therefore, calls for an examination of the nature and form of the international community, including international institutions and practices, which is an essential missing part of Singer's theory (Blake, 2010). 


\section{Pogge's No Harm Principle and Negative Duty}

Singer advocated an active duty of assistance from developed countries to developing countries to alleviate the health crisis that prevailed in the latter. Such obligations, in turn, are characterized by the requirement that developed countries and their peoples donate a certain proportion of their gross domestic product or income to developing countries. This statement reflects the great concern about the health problems related to poverty. After all, intuitively, if poverty can be eliminated, many health problems can be "solved."

On the other hand, some scholars have suggested that in order to solve the health crisis of developing countries, developed countries should bear a negative obligation to developing countries, which is manifested in that developed countries can not impose a harmful global institutional order on developing countries. Otherwise, they should make corresponding compensation and reform this harmful global order. For example, Thomas Pogge points out that each of us has strong moral reasons to ensure that our actions do not harm others. If others are hurt by your fault, you have stronger moral reasons to help these victims than others are hurt by other factors, which are out of your control. Similarly, if the Governments of rich countries and the global institutional order that they support and actively promote substantially lead to the occurrence of medical conditions in poor countries, then rich countries violate a negative obligation to ensure that any institutional order they support does not harm poor countries, then rich countries have a responsibility to mitigate and eliminate such medical conditions and to bring about changes in that institutional order (Pogge, 2002).

One of the premises of Pogge's argument is that poverty is the most important factor contributing to the existing health crisis in developing countries. On this basis, another famous assertion by Pogge is that the characteristics of the current global order have led to large-scale extreme poverty, which continues and can be predicted to produce extreme and premature deaths (Pogge, 2005). Because rich countries have great advantages in negotiating power and professional skills, he argues, rich countries and their negotiators can use them to influence the arrangements of the global order to make it more in the interests of their governments, companies and citizens, which in the end deviates the program best to avoid poverty. This has led to the growing marginalization of the global poor, whose interests have been ignored both in domestic and international decision-making. Governments and citizens of rich countries are, therefore, primarily responsible for the current global institutional arrangements.

If the current global institutional order imposed by developed countries had resulted in large-scale extreme poverty, which, as one of the most important factors, had led to a health crisis in developing countries, developed countries had harmed them in the area of health. Thus, developed countries have violated their negative obligation not to participate in the implementation of an institutional order that would harm developing countries. Then developed countries have a duty to compensate for the harm they have caused.

Although Pogge's view has great attraction, there are some problems in his argumentation. Even if the global institutional order imposed by the developed countries harmed the developing countries and should therefore be held liable for compensation, according to the argument that the developed countries should assume a negative duty of no harm to the developing countries, the developed countries need only eliminate the elements of the existing institutional order that hurt the developing countries, but do not have the obligation to support a global institutional order that benefits the developing countries. In other words, "no harm" does not equal support. 
Second, both Singer and Pogge believe that public health problems in developing countries are primarily caused by poverty. I do not want to deny this, but I just want to say that there is a lot of evidence that even in impoverished areas, it is possible to maintain a more desirable public health. An example of this was reported in the World Health Report 2008: the economic situation in the Congo has deteriorated sharply over the past 30 years. Despite the withdrawal of State support from the health sector and the worsening of large-scale poverty, primary health-care services in Rutshuru, an area in eastern Democratic Republic of the Congo, did not collapse, on the contrary, the number of health centers and services provided have increased, and the quality of care for patients with acute and chronic diseases has improved. These results clearly benefit from a robust health-care system in the region. Through the experience of Rutshuru regions, WHO pointed out that regional health care guided by the primary health care system is a robust organizational model that can withstand extreme adverse environments. It can be seen that internal institutional factors can not be ignored in the public health situation of a country and a region. But neither Singer nor Pogge considered this point.

Therefore, although the philosophical plans proposed by Singer and Pogge for global public health problems have their own attractiveness, both of them have theoretical deficiencies and lead to shortcomings in dealing with the global public health crisis. In the last part of this paper, I try to develop Rawls' theory to put forward my own opinion on this issue. In my opinion, although, regrettably, Rawls has not specifically addressed the issue of global public health, his argument about assistance obligations provides an instrumental approach for us to address it.

\section{Why A Law of Healthy People?}

\section{Loopholes of Rawls'Law of Peoples}

Rawls does not address global health directly in The Law of Peoples. Like singer and Pogge, Rawls is simply trying to make his own philosophical claims about global poverty. In the non-ideal part of the Law of Peoples, Rawls argues that free and decent people should undertake an obligation of assistance to burdened society in order to help the latter establish a reasonable and just or decent system. "Burdened societies, while they are not expansive or aggressive, lack the political and cultural traditions, the human capital and know-how, and, often, the material and technological resources needed to be well-ordered" (Rawls, 1999).

A well-ordered society should follow three guidelines in implementing its assistance obligation. The first rule is that a well-ordered society does not need to be productive. "Great wealth is not necessary to establish just (or decent) institutions. How much is needed will depend on a society's particular history as well as on its conception of justice" (Rawls, 1999). The second criterion is to realize the importance of the political culture of the overburdened society when thinking about how to implement assistance obligation. "The causes of the wealth of a people and the forms it takes lie in their political culture and in the religious, philosophical, and moral traditions that support the basic structure of their political and social institutions, as well as in the industriousness and cooperative talents of its members, all supported by their political virtues (Rawls, 1999). Rawls stresses that there is a little recipe for well-ordered people to help burdened societies to change their political and social culture. But the emphasis on human rights will change inefficient institutions and the behavior of rulers who are indifferent to the welfare of their people. The third criterion for fulfilling assistance obligations is that assistance is intended to help burdened societies, enable them to manage 
their own affairs reasonably and rationally, and eventually become members of the Society of well-ordered Peoples. When this is achieved, no more assistance will be required, even if the well-ordered society may still be relatively weak.

From Rawls' definition of a burdened society, he does not seem to notice the serious impact that the public health crisis may have on a community. The reality is that, since the 1990s, the spread of HIV has led some African countries to lose early gains. The severe AIDS crisis has led to a significant decline in average life expectancy at birth in some of the world's poorest countries and a sharp increase in the gap with richer societies. The widespread morbidity and mortality from diseases such as AIDS and malaria can significantly reduce agricultural productivity and destroy farmers' livelihoods. However, the shortage of labor due to public health problems is clearly much more severe than the lack of human capital and know-how, material, and technical resources.

Of course, we cannot ask Rawls to explore all the issues in The Law of Peoples. Rawls himself points out, "As a consequence of focusing on the idea of a realistic Utopia, many of the immediate problems of contemporary foreign policy that trouble citizens and politicians will be left aside altogether or treated only briefly" (Rawls, 1999). However, the global health problem is closely related to the Law of Peoples as a "Realistic Utopia," so it can not be ignored. As we all know, the central theme of Rawls' domestic theory of justice is the basic structure of society, that is, the distribution of basic rights and obligations by the leading social system and the way to determine the distribution of benefits arising from continuous social cooperation. Social cooperation is different from simple social adjustment activities, such as those regulated by an order issued by a central authority; on the contrary, social cooperation is guided by publicly recognized rules and procedures, and contains the idea of equitable conditions of cooperation, which each participant can reasonably accept (Rawls, 1993).

It can be seen that one of the important characteristics of Rawls' idea of social cooperation is that social cooperation is voluntary rather than forced, and the individual citizens involved in it should bear responsibility for their actions (Freeman, 2007). This will inevitably require the ability of the members involved in social cooperation, which Rawls has many times stressed. "A decent hierarchical society's conception of the person, ... Rather it views persons as responsible and cooperating members of their respective groups. Hence, persons can recognize, understand, and act in accordance with their moral duties and obligations as members of these groups" (Rawls, 1999). It is natural to simplify this problem in ideal theory. However, the failure of the obligation to assist as part of the non-ideal theory to explore the incapacity caused by public health problems is the theoretical loopholes of the Law of Peoples. And this lack also makes Rawls set too low a standard for the decentness of the peoples to ensure their members' ability to participate in social cooperation.

According to Rawls, the conditions for the decent peoples to become members of Society of Peoples, i.e., the criteria for decentness are: first, that the decent peoples recognize the need to achieve their legitimate goals through peaceful means, such as diplomacy and trade, rather than aggression; second, that the proper people's legal system is guided by its common good philosophy of justice to ensure the human rights of its members; and that it imposes moral duties and responsibilities of goodwill on all within its territory; and that the practitioners of the legal system, judges and government officials, indeed, have a reasonable belief that the law is guided by a common good philosophy of justice (Rawls, 1999). Among them, to ensure that their members enjoy basic human rights is an important requirement for the people to be decent. The list of human rights listed by Rawls includes the right to life, liberty, property, 
formal equality, as expressed in the rules of natural justice, etc. In this human rights list, the right to life is most relevant to global health issues. Rawls says the right to life has a very broad connotation, including the right of people to various measures and means to maintain survival and security (Rawls, 1999).

Rawls' view of human rights is very closely related to the American scholar Henry Shue's exposition on "basic rights." Shue argues, A moral right provides (1) the rational basis for a justified demand (2) that the actual enjoyment of a substance be (3) socially guaranteed against standard threats. The substance of a right is whatever the right is a right to. A right is not a right to enjoy a right — it is a right to enjoy something else, like food or liberty. And standard threats, are those common, or ordinary, and serious but remediable threats. Shue continues to claim that, "if a right is basic, other, non-basic rights may be sacrificed, if necessary, in order to secure the basic right. But the protection of a basic right may not be sacrificed in order to secure the enjoyment of a non-basic right. It may not be sacrificed because it cannot be sacrificed successfully. If the right sacrificed is indeed basic, then no right for which it might be sacrificed can actually be enjoyed in the absence of the basic right. The sacrifice would have proven self-defeating" (Shue, 1980).

In practice, the primacy of basic rights usually means that they must first be firmly established before other rights can be ensured. Because people not only "have" other rights in a certain law-abiding or abstract sense, but also use the content of rights. So the key point is that people can "enjoy" or "exercise" other rights. Shue claims three basic rights: (1) the right to (physical) security, i.e., the right to be free from murder, torture, injury, rape or sexual abuse; and (2) the right to subsistence, or the minimum right to economic security, i.e., free from pollution of air and water, adequate food, clothing and shelter, and minimum preventive public health care; (3) The right to freedom. All types of basic rights correspond to three types of obligations: (1) the obligation to avoid deprivation and not to deprive others of the content of their basic rights; (2) the obligation to protect others from deprivation; and (3) the obligation to assist, the obligation to assist those who are deprived (Shue, 1980).

Shue points out that his purpose in writing "basic rights" is to discuss the right to subsistence, that is, the basic core content of the so-called "economic rights," should belong to the right to be given priority. In contrast to the right to security, the right to subsistence as a basic right is highly controversial. While recognizing that the right to subsistence and security are essential for the maintenance of life, many scholars tend to view the right to subsistence as second in importance to the right to security. One important difference is that the right to security is a "negative" right, while the right to subsistence is a "positive" right. A positive right requires others to do something, while a negative right simply requires others to refrain from doing something, i.e., not doing anything that violates the right. However, Shue believes that it is wrong to divide the right to subsistence and the right to security according to the dimension of positive/negative rights, because both of them correspond to positive and negative obligations, so trying to divide rights rather than obligations into positive rights and negative rights can only be misleading. At the same time, since the argument that the right to security is a fundamental right can be similarly applied to the right to existence, it is natural to conclude that the right to existence is also a fundamental right.

Fundamental rights are minimum reasonable claims that everyone can make against others. This minimum requirement can be made by everyone and must be met at least by anyone, any government, and community. A moral minimum is embodied in such a minimum requirement, i.e., a threshold for tolerating human behavior, whether personal or institutional. 
The fundamental rights concept of Shue has had an essential impact on Rawls' view of human rights. Rawls also points out that human rights in The Law of Peoples manifest a special category of emergency rights and set a necessary rather than sufficient standard for the suitability of domestic political and social systems. Such a standard is a "minimum standard," so it is not convincing to demand the waiver of these rights (Rawls, 1993).

Under such a standard, human rights in The Law of Peoples include the following rights: (1) The right to life: including the right to all means of subsistence, the right to security; (2) The right to freedom: including freedom from slavery, serfdom and forced labor, and effective measures for freedom of conscience to ensure freedom of religion and freedom of thought; (3) Property rights: acquisition of individual property rights; (4) The right of association; (5) The rights of emigration: such rights should not be mere formal rights, but people should also provide assistance to migrants where possible (Rawls, 1999).

From the above, Rawls' understanding of the meaning of the right to life directly refers to Shue's elaboration on the right to security and the right to subsistence, and expresses his agreement with Shue's assertion that the right to subsistence is a basic right. But the right to subsistence is the right to free air and water from pollution, adequate food, clothing and shelter, and minimal preventive public health care, so that a suitable opportunity can be obtained to achieve a life of almost normal length and considerable health and vitality. The interpretation of the right to subsistence was made more than 20 years ago, when there was no serious public health crisis caused by diseases such as AIDS, and the global environmental problems were far from serious today, so that the content of the right to subsistence contained only air and water free from pollution, adequate food and shelter, and minimal preventive public health care, which did not fully reflect the right to health. But Rawls fails to break through the concept of the right to subsistence and construct a law of "healthy" peoples that incorporates the right to health in the context of the global public health crisis nearly 20 years later, which is really regrettable.

\section{A Law of "Healthy” Peoples: Development of Rawls' Law of Peoples}

The author thinks that Rawls' ambivalence reflects his hesitancy about whether the right to subsistence fits a neutral view of human rights. Rawls emphasizes the objectivity of the Law of Peoples, which is manifested in that the content of The Law of Peoples does not depend on the time, place or culture of its origin, but on whether it meets the criterion of reciprocity and whether it belongs to the public reason of free or decent people's society. To this end, Rawls advocates a neutral view of human rights. This neutrality is reflected in: (1) human rights are one of the most important ethical considerations, as they impose a minimum requirement of legitimacy on political power; and (2) human rights have broad applicability and applies to almost all countries, regardless of their political traditions, economic level, and legal system; (3) human rights have ideological neutrality, i.e., human rights are a common concern of any ideological category of government; and (4) human rights issues are separable from partisan politics, meaning that requiring a state to end human rights violations does not necessarily require a change in its political system (Scanlon, 2003).

In fact, from Rawls' related exposition, he does not try to deny the importance of the right to subsistence or any other similar rights, the key lies in how to demonstrate and determine the connotation or content of the right to subsistence, which Rawls failed to provide us with an answer or a question that seems to be avoided by him. When Shue tells us that the 
right to life refers to the right to free air and water, adequate food and shelter, and minimal preventive public health care, there is also a lack of adequate justification. Naturally, this is a rather difficult problem, but I think a minimum right to health must be covered by the right to subsistence or any similar right, which forms the basic needs that should be met by both free and decent people.

From the right to subsistence to the right to health, it seems to be moving from one maze to another. while the content of the right to health is enshrined in The Universal Declaration of Human Rights and The International Covenant on Economic, Social and Cultural Rights, the existence of the concept of the right to health and its definition remain questionable, and the concept of the right to health appears to be self-defeating - how can the full state of health of the individual be ensured? After all, this is a very subjective question, even if two people live in the same environment, and can get the same living conditions and medical conditions, the health of both is still likely to differ significantly. Just as The UN Committee on Economic, Social and Cultural Rights mentioned, "genetic factors, individual susceptibility to ill health and the adoption of unhealthy or risky lifestyles may play an important role with respect to an individual's health" (The UN Committee, 2000).

However, recognition of this does not necessarily lead to a denial of the right to health, but only makes it clear that the definition of the right to health must exclude subjective factors that have an important impact on health. If a person who knows that smoking and drinking can lead to certain diseases is still doing so, which ultimately results in impaired health, this can not be attributed to anyone, nor can it be said that his or her right to health is impaired. Therefore, the right to health must not be understood as the right of everyone to (maintain) complete health, which is neither possible nor realistic; on the contrary, I agree to some extent with the interpretation of the Committee on Economic, Social and Cultural Rights, "the right to health must be understood as a right to the enjoyment of a variety of facilities, goods, services and conditions necessary for the realization of the highest attainable standard of health" (The UN Committee, 2000).

We may refer to these "facilities, goods, services, and conditions" as objective conditions for access to health to distinguish the aforementioned subjective factors. These objective conditions are the content of the right to health that we should discuss. Therefore, the content of the right to health can neither be exhaustive nor too narrow. First, there is no doubt that the right to health is closely related to other human rights, and if people are exposed to torture, injury, and lack of personal freedom, then the right to health is difficult to achieve. However, since these elements are already covered by the right to security, their inclusion in the right to health is cumbersome and unnecessary.

Secondly, countries have different levels of economic development and different access to resources, so that the welfare systems of some developed countries can not be taken as part of the right to health. Otherwise, as Rawls puts it, some kind of system or just an expectation is presupposed, and consensus can not be reached within the community of peoples. On the other hand, the content and standards of the right to health can not be too low and too narrow, and must cover something that can not be derogated from under any circumstances, otherwise it loses its meaning and value as a moral threshold.

Based on these considerations, the right to health should include three levels. First, environmental conditions. As discussed above, a safe and healthy living environment has an important impact on human health. The recent history has sharply reminded people of the important link between human health and environmental conditions. These environmental 
conditions, in addition to what Shue says pollution-free air and water, are pollution-free land, living space free from radiation of radioactive materials, etc.

Second, living conditions. Including basic food, clothing, and shelter to protect people from hunger and cold. The enjoyment of safe and adequate food from hunger is part of the right to health that everyone should enjoy. On the other hand, basic housing can not be understood to mean that everyone has a house as private property, but at least everyone has access to shelter from the wind and rain. For this reason, the author prefers "shelter" to "housing supply."

Third, basic health care and medical conditions. Health care encompasses all goods and services (systems) designed to protect and promote health, including interventions for the prevention, treatment, and mitigation of disease, whether directed at individuals or the general population. What Shue calls "minimal preventive public health care" is only part of it. To that end, it is essential to have hospitals, clinics and other medical facilities and services that meet the needs, and to have qualified health-care staff, including doctors and other medical personnel. These facilities, goods and services, and especially those essential medicines, regardless of the specific medical system adopted, should be accessible to all at a reasonable cost and not beyond their affordability.

It can be seen from the above that the right to health corresponds to certain obligations. The author thinks that, according to Shue's view, the obligation corresponding to the right to health also contains both positive and negative obligations, and the two requirements are sometimes difficult to separate completely. In particular, states have an obligation to provide their populations with environmental, living, health and medical conditions that meet at least the above requirements, in accordance with their respective levels of development, and to that end take appropriate legislative, administrative, judicial, budgetary and policy initiatives to protect and promote their realization (positive obligations). The positive obligations of states to that end are clear. At the same time, states also have a negative obligation to refrain from polluting environment such as air, water, and land under various pretexts, in particular by avoiding the release of harmful substances from nuclear testing and the nuclear industry, harming human health by avoiding the imposition of harmful traditional cultural practices on individuals and by preventing access to information and resources on health care, especially for vulnerable groups. This negative obligation is also sometimes manifested in the fact that states cannot allow third-parties to limit and impair the right to health of their people and remain indifferent.

If a state is unable to meet these obligations within its own resources, other States and international organizations have an obligation to assist it for the realization of the essential elements of the right to health. In particular, in emergencies, including public health crises, where a state is unable to respond on its own, other states should provide it with goods and services in a reasonable manner. Similarly, other states and international organizations should respect the right to health enjoyed by people in other countries and ensure that mechanisms, measures, and actions do not adversely affect the right to health. Thus, the transfer of contaminated waste to developing countries by developed countries violates the negative obligation of the right to health.

Thus, the expansion of the right to life referred to in Rawls' Law of Peoples is interpreted as including at least a minimum right to health concept, and the author tries to provide a Rawlsian perspective for dealing with the global public health problems: a Law of Healthy Peoples. I believe that Rawls does not take into account the severe reality of the global health crisis in The Law of Peoples and make a corresponding philosophical reflection on it, which 
is inconsistent with the idea of "The Law of Peoples as Realistic Utopia." In a Law of Healthy Peoples, however, one of the criteria for the decentness of the people is to ensure that their members enjoy the right to health; in non-ideal theory, the criterion for judging a burdened society is that they not only lack the political and cultural traditions, human capital and knowhow, as well as material and technical resources necessary to become a well-ordered society, but may also be societies that are threatened by a public health crisis. It is the duty of free and decent people to assist the burdened society in order to help the latter build a just or decent society.

Thus, in The Law of Healthy People, the right to health is regarded as a fundamental human right, and its realization becomes one of the important criteria for decentness. At this point, inequality in the health of peoples can be analyzed in Rawls' view that inequality is not always unjust, when it is unjust, because it has an unjust effect on the basic structure of the society of peoples and on the relations between peoples and their members. Thus, inequalities in the health status of peoples can be manifested in two situations: first, not only are there many inequalities, but some states do not have access to the basic content of the right to health. Secondly, despite inequalities, states have ensured the realization of the right to health in a just or decent system. In the first case, where people in some countries are not guaranteed even the most basic human rights, where life and health are at great risk, and where differences can cause them to feel inferior and undermine their self-esteem, such inequalities can not be justified and need to be addressed to alleviate the suffering and inferiority that people suffer. In the second case, where the content of the right to health has been realized, and people's right to health is guaranteed, the health status of people may vary across countries, but this inequality can not be said to be unjust at this time. As mentioned earlier, complete health or good health conditions can not be guaranteed. If people try to improve their overall health condition, they can continue to optimize their resource allocation and institutional design while working to establish an excellent cultural practice conducive to life and health.

Compared with Singer and Pogge's research plan, The Law of Healthy People has strong theoretical inclusiveness. It can be seen from the discussion above that both positive duty to assist and negative duty of no harm are both insufficient. And after incorporating the concept of the right to health into The Law of Peoples, the purpose of the duty of assistance is to help burden society to establish a just or decent system that ensures the realization of the right to health. The obligation of the right to health itself contains both positive and negative requirements. Therefore, from this perspective, The Law of Healthy People has actually covered both Singer and Pogge's theory.

On the other hand, there is still a clear difference between The Law of Healthy Peoples and the research approach of Singer and Pogge. Both Singer and Pogge reflect on global health only from external factors, not on internal factors. However, the aforementioned example of the Rutshuru vividly illustrates the significant impact of internal institutional factors on the overall health of the population. This is in line with the argumentation of The Law of Healthy Peoples since the ultimate aim of the duty of free and decent people to assist a burdened society is to help build up within it a system to ensure the realization of the right to health, rather than simply giving material resources. Under such a goal, the assistance of material resources from outside may be necessary, but not sufficient. For example, with regard to the fight against AIDS in developing countries, developed countries should be required to provide basic antiviral drugs to developing countries at a reasonable cost. At no time should intellectual property rights protection be used as grounds to prevent access to adequate essential medicines and related 
medical facilities, much less as a means of political pressure. This is a positive and negative obligation of other states to which the right to health corresponds. At the same time, however, developing countries are called upon to take initiatives to eliminate traditional and customary practices actively: in some countries, for example, husbands consider it unacceptable that their wives refuse to have sexual relations with them, and they even take unprotected sex as their right. Because of such practices, it is difficult for these countries to curb the AIDS epidemic.

\section{Conclusions}

There are striking differences in the health status of people around the world. Although Peter Singer and Thomas Pogge's philosophical proposals on global public health are attractive to some extent, they both have theoretical deficiencies in dealing with global public health problems. Rawls does not address global health directly in The Law of Peoples, but tried to put forward his own philosophical claims on global poverty. In the non-ideal part of Law of Peoples, Rawls argues that free and decent people should shoulder a duty of assistance to burdened society in order to help the latter establish a reasonable, just or decent system. Rawls' burdened society shows that he has not noticed the serious impact that the public health crisis may have on a society, which is inconsistent with the idea of "The Law of Peoples as Realistic Utopia." This loophole has led Rawls to set too low a standard of decentness for peoples, as reflected in Rawls' view of human rights, which fails to fully reflect the connotation and requirements of the right to health. To this end, the author argues that a minimum sense of the right to health should be incorporated into the The Law of Peoples to build a Law of Healthy Peoples. The right to health includes certain environmental conditions, living conditions, basic health and medical conditions, and has become one of the important criteria for decentness. Free and decent peoples must assist burdened societies in order to help the latter establish a reasonable, just or decent system, thus ensuring the realization of the right to health in the last. The Law of Healthy People has a strong theoretical inclusiveness, which can make up for the shortcomings of Singer and Pogge's theory.

\section{미] References}

Blake, Michael (2010) "International Justice (Stanford Encyclopedia of Philosophy)," http:// plato.stanford.edu/entries/international-justice/, last visited on 13 October, 2010.

Freeman, Samuel (2007) Justice and the Social Contract: Essays on Rawlsian Political Philosophy, Oxford University Press.

Pogge, Thomas (2002) Responsibilities for Poverty-Related Ill Health, Ethics and International Affairs, Vol. 16, No. 2.

Pogge, Thomas (2005) Recognized and Violated by International Law: The Human Rights of the Global Poor, Leiden Journal of International Law, Vol. 18, No. 04, December 2005.

Rawls, John (1999) The Law of Peoples. Cambridge, MA: Harvard University Press.

Rawls, John (1993) Political Liberalism, New York: Columbia University press.

Rawls, John (1993) The Law of Peoples, Critical Inquiry, Vol. 20, No. 1 (Autumn, 1993).

Scanlon, T.M. (2003) The Difficulty of Tolerance: Essays in Political Philosophy, Cambridge University Press.

Singer, Peter (1972) "Famine, Affluence, and Morality," Philosophy and Public Affairs 1.

Singer, Peter (2011) Practical Ethics, Cambridge University Press.

Singer, Peter (2016) One World Now: The Ethics of Globalization, Yale University Press. 
Toward a law of healthy peoples: From the Perspective of the Right to Health by Yusheng Tan

Shue, Henry (1980) Basic Rights: Subsistence, Affluence, and U.S. Foreign Policy, Princeton: Princeton University Press.

The UN Committee on Economic, Social and Cultural Rights, "The right to the highest attainable standard of health" (2000) Doc. E/C.12/2000/4, 11 August 2000. 